DOI:

УДК 621.38:004.383.3:

В.В. Багрій, к.т.н., доцент,

А.І. Трикіло, к.т.н., доцент,

Р.В. Волошин, завідувач лабораторії.

Дніпровський державний технічний університет, м. Кам'янське

\title{
УДОСКОНАЛЕННЯ РЕНТГЕНІВСЬКОЇ КОМП'ЮТЕРНОЇ ТОМОГРАФІЇ
}

Рентгенівська комп'ютерна томографія (РКТ) нині є найбільи перспективним і найбільи інформативним методом діагностики. За допомогою апаратури томографії можна отримати знімки безлічі перерізів тіла пачієнта, які характеризують особливості його анатомії і фізіології.

Ключові слова: рентгенівська комп'ютерна томографія; 3D-зображення; піксель; математична модель; обробка зображень.

$X$-ray computed tomography (X-ray CT) is now the most promising and informative method of diagnosis. With the help of tomography equipment, images of many sections for the patient's body can be obtained that characterize the features of his anatomy and physiology.

Keywords: $x$-ray computed tomography; $3 D$ images; pixel; mathematical model; image processing

\section{Постановка проблеми}

Математичні методи обробки зображень дозволяють реконструювати тривимірну структуру органів по безлічі паралельних перерізів. Комп'ютерний томограф включає джерело випромінювання; екран-перетворювач, випромінювання реєстрування; пристрій перетворення початкових даних в цифровий код; процесор і програмне забезпечення, що реалізовує алгоритм тривимірної реконструкції (рис. 1).

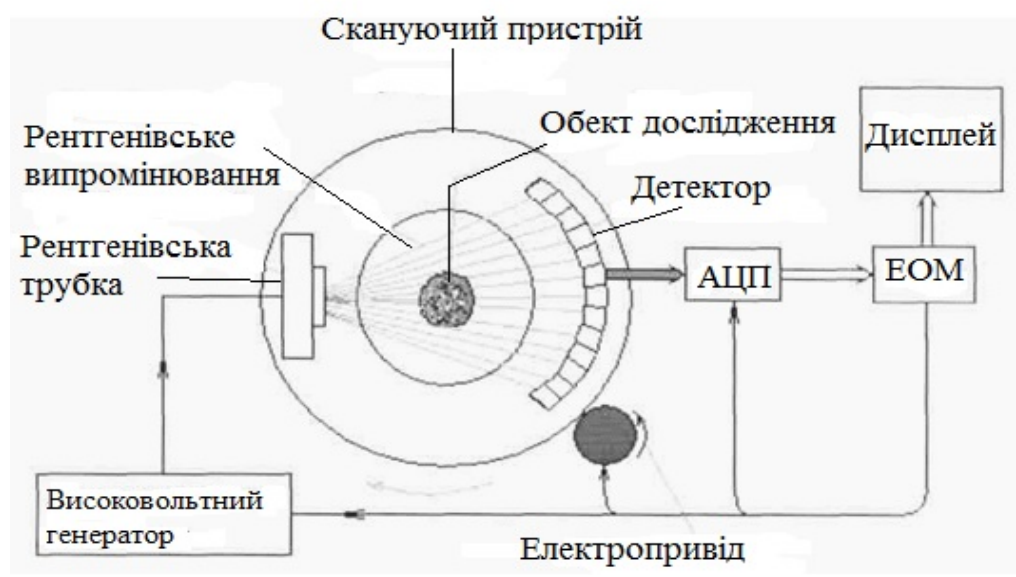

Puc. 1. Структурна схема комп'ютерного томографа

Принцип роботи комп'ютерного томографа припускає отримання двовимірних дискретних зображень (зрізів) з точно вивіреним кроком. Для остаточної чіткої достовірної діагностичної картини великого значення набувають методи подальшої обробки зображення. Якщо припустити, що у міру переходу від одного перерізу до іншого об'єкт не устигає змінитися, то створюваний сканером набір двовимірних дискретних зображень (дискретна тривимірна сцена) $\epsilon$ тривимірною множиною елементарних об'ємів [1]. 
Спрощена схема побудови тривимірного зображення представлена на рис. 2. У зв'язку з тим, що відстань між зрізами значно більше відстані між точками (пікселями) на самому зрізі, використовується алгоритм побудови додаткових, проміжних зрізів шляхом знаходження середньо арифметичних значень точок попереднього і наступного зрізів. В результаті отримують тривимірну матрицю, за допомогою якої відновлюється тривимірне зображення. Залежно від призначення дискретні тривимірні сцени, що створюються сканерами, дають інформацію про структуру об'єкту і (або) про його функціональний стан [1-2].

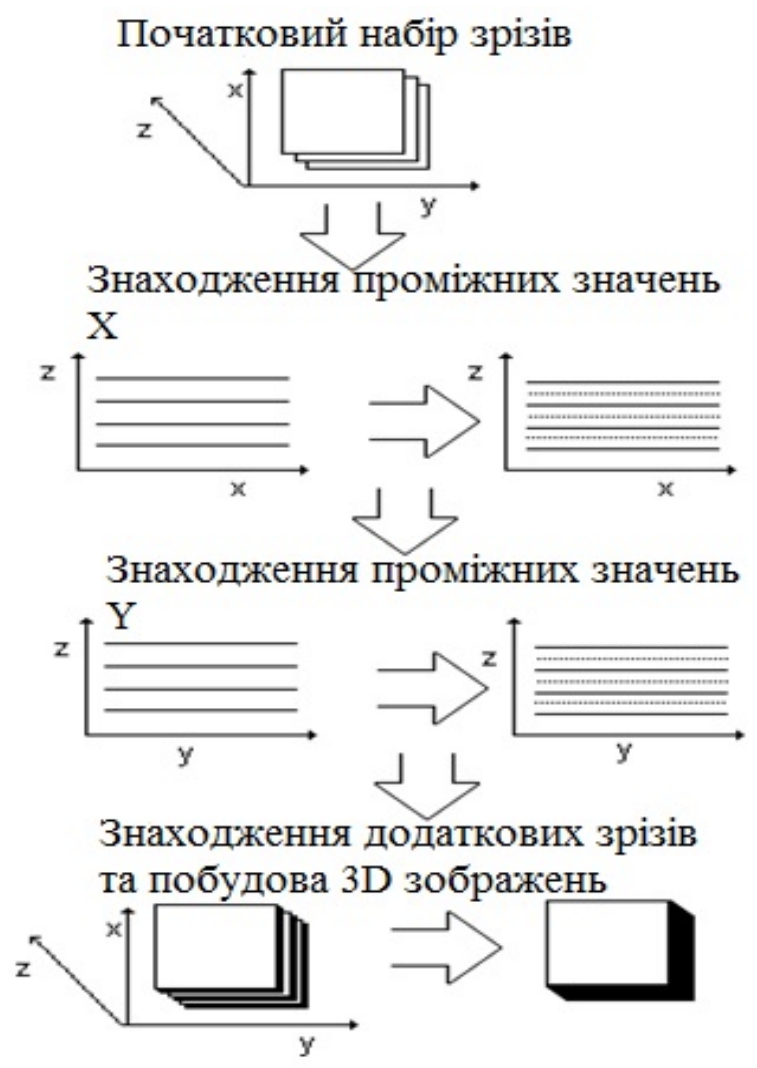

Puc. 2. Структурна схема побудови 3х-мірного зображення

Аналіз останніх досліджень і публікацій

Слід зазначити, що в реальних умовах неможливе отримання точної реконструкції 3D-зображення. Згідно з джерел це пов'язано з погрішностями вимірів проекційних даних, кінцевими кроками дискретизації переміщень сканера і іншими допущеннями. При розробці методів представлення інформації про будову і форму тривимірних дискретних зображень діють по аналогії з двовимірним зображенням [2-4].

Найбільш природним і прямим способом відображення двовимірних дискретних зображень $\epsilon$ такий спосіб, при якому кожній точці екрану повідомляється яскравість, пропорційна щільності відповідного елементу у відтворному зображенні. Я позначено в роботах Наступний крок полягає в ідентифікації різних об'єктів, представлених в об'ємних даних так, щоб їх можна було виділити для візуалізації або, навпаки, зробити невидимими. Цей крок включає сегментацію і інтерпретацію. Простий спосіб полягає в бінаризації даних з використанням порогу інтенсивності, наприклад, для виділення кісток з інших тканин в комп'ютерній томографії. Проте в деяких випадках потрібно тонші методи сегментації. Наприклад, об'єм зазвичай включає велике число різних структур, що затінюють одна одну [4]. Для того, щоб зображувати одну з них, слід вирішити, яку частину даних необхідно використовувати, а яку ігнорувати. У ідеалі, вибір має бути зроблений за допомогою команди типу "покажи тільки мозок". Проте для цього вимагається, щоб комп'ютер знав, які частини об'єму відносяться до мозку, а які ні [4-6]. 


\section{Формулювання мети дослідження}

Основною метою даної роботи є розробка первинної обробки даних, з використання оптимального інерційно-форсуючого фільтру Вінера першого порядку для удосконалення рентгенівської комп’ютерної томографії.

\section{Виклад основного матеріалу}

Першим кроком розпізнавання об'єкту має бути розподіл об'єму на різні області, які $є$ однорідними по відношенню до деякого формального критерію і відповідають реальним (анатомічним) об'єктам. Такий процес називається сегментацією. $Є$ велика кількість методів сегментації для 3D медичних зображень, які можна розбити на три типи,: методи на основі точок, меж і областей [4].

При сегментації на основі точок, вокселі класифікуються тільки відповідно до величини їх інтенсивності. Добре відомі такі методи, як розпізнавання патернів і нейронні мережі. При сегментації на основі меж, в зображуваному об'ємі визначають неоднорідність в розподілі інтенсивності, використовуючи для цього перші або другі похідні. При сегментації на основі областей, розглядаються властивості цілих областей, такі як розмір або форма. Часто використовується комбінація декількох різних підходів.

Після сегментації виникає проблема, який з методів рендерингу (обробки зображення) використовувати далі. Відносно нещодавно були розроблені підходи, засновані на воксельному представленні об'ємів, які створюють тривимірні зображення об'єкту безпосередньо з об'ємних даних [5]. Ці методи використовують повну інформацію про значення інтенсивності півтонового зображення для рендерингу поверхонь, розрізів або прозорих і напівпрозорих об'ємів. Способи воксельного рендерингу, які розрізняються, головним чином, стратегією сканування: піксель за пікселем (впорядкування по зображенню) або воксель за вокселем (впорядкування за об'ємом) на сьогодні являються, мабуть, найбільш інформативними. При скануванні з впорядковуванням по зображенню об'ємні дані вибираються на променях уздовж напряму спостереження. Цей метод відомий як метод відстеження променя. Уздовж променя легко визначається видимість поверхонь і об'єктів. Промінь може зупинитися, коли на його шляху зустрічається непрозора поверхня. Метод відстеження променя $\epsilon$ дуже гнучким і добре зрозумілим прийомом сканування. Він дозволяє порівняно легко поєднувати методи рендерингу для непрозорих, напівпрозорих і прозорих поверхонь. Крім того, сканування по зображенню можна одночасно використовувати для рендерингу як воксельних, так і поверхневих даних [6]. Якість зображення можна змінювати, збільшуючи або зменшуючи крок вибірки даних. 3 іншого боку, застосовність алгоритмів відстеження променя обмежується вимогами великого об'єму пам'яті і високої потужності комп'ютера. Для того, щоб об'єкт можна було розглядати з різних напрямів, необхідно забезпечити довільний доступ до усіх вхідних об'ємних даних. Крім того, для косих променів потрібно інтерполяцію інтенсивності в точках вибірки даних.

Тривимірні зображення можна отримати, виходячи і з інших представлень даних. Один 3 таких методів - рендеринг в частотних областях, який створює 3D-зображення в просторі Фур'є. Це дуже швидкий метод, хоча його застосовність обмежена досить простими інтегральними проекціями. Перспективніший підхід використовує вейвлет-перетворення, яке створює мультимасштабне представлення 3D об'єктів і дозволяє локально регулювати розміри деталей, що відображуються, i, як наслідок, скоротити кількість даних і час рендерингу. Слід зазначити, що для отримання достовірних діагностичних даних первинне зображення, що піддається обробці вищезгаданими методами, повинне мати мінімальні погрішності, пов'язані з особливостями апаратурного забезпечення методу $[6,8]$.

Одним із способів поліпшення якості отримуваного в комп'ютерній томографії зображення $є$ удосконалення первинної обробки сигналів, яка дозволяє зменшити вплив різних перешкод на результати дослідження. Для зменшення впливу шумів і артефактів на подальшу обробку інформації і витягання з нього корисної складової широко застосовуються дискретне перетворення Фур'є, швидке перетворення Фур'є, цифрові фільтри і вейвлет-перетворення. Як видно із структурної схеми обробки сигналу (рис. 3), на датчик поступає зашумлений сигнал. Для виділення корисної складової сигналу застосовують цифровий або аналоговий фільтри [8]. 


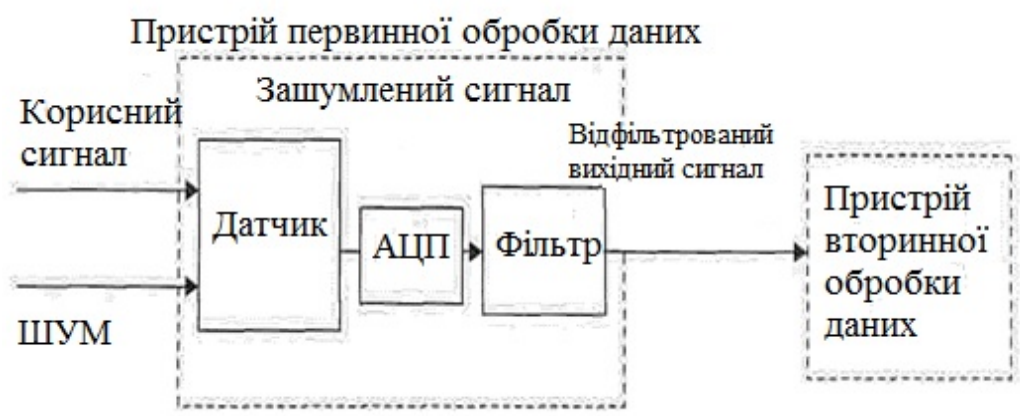

Рис. 3. Структурна схема обробки сигналу

Поширена перешкода в колах виміру — це білий шум. Проте, ніж складніша процедура отримання первинної інформації, тим більше перешкода відрізняється від білого шуму і стає кольоровою. Ї̈і математична модель може бути складніша, ніж модель корисного сигналу. Тому задачу фільтрації вирішують для найбільш поширеного вузького набору початкових характеристик. У найпростішому випадку сигналів що не містять періодичні складові, моделі корисного сигналу і перешкоди співпадають за формою, але відрізняються параметрами.

Для корисного сигналу:

$$
K_{y}(\tau)=\sigma_{y}^{2} \exp (-\alpha \tau)
$$

для не корельованої перешкоди довільної форми:

$$
K_{\Theta}(\tau)=k \sigma_{y}^{2} \exp (-m \alpha \tau),
$$

де $\sigma_{y}^{2}$ - дисперсія корисного сигналу; $\alpha$ - параметр загасання автокореляційної функції корисного сигналу, Гц; $k$ - коефіцієнт відношення дисперсій перешкода-сигнал (звичайно менше одиниці); $m$ - параметр частотного діапазону перешкоди.

Великий практичний інтерес представляє вузькосмугова перешкода, коли параметр $m$ менше одиниці. При $m \geq 1$ частотний діапазон перешкоди порівнюється з корисним сигналом, а потім стає ширше за корисний сигнал. У граничному випадку при $(m=\infty)$ трансформується в поширену модель білого шуму:

$$
K_{\Theta}(\tau)=G_{\Theta} \delta(\tau)
$$

де $G_{\Theta}$ - інтенсивність білого шуму.

Синтезуємо фільтр, який забезпечує виділення корисного сигналу $y(t)$, що спостерігається 3 адитивною не корельованою перешкодою $\Theta(t)$. Фур'є - перетворення дозволяє записати спектральну щільність сигналу і перешкоди:

$$
\begin{gathered}
S_{y}(\omega)=\frac{\sigma_{y}^{2} \alpha}{\pi} \frac{1}{\alpha^{2}+\omega^{2}}, \\
S_{\Theta}(\omega)=\frac{\sigma_{y}^{2} \alpha}{\pi} \frac{m k}{m^{2} \alpha^{2}+\omega^{2}} .
\end{gathered}
$$

Ідеальний сигнал на виході в завданні відтворення сигналу на тлі перешкоди:

$$
h_{T}(t)=y(t) .
$$

Область спостереження вхідного сигналу нескінченна, що практично відповідає умові значного перевищення інтервалу спостереження над часом корекції вхідного сигналу.

Частотна характеристика оптимального за критерієм мінімуму сталої середньоквадратичної помилки фільтру Вінера має вигляд: 


$$
H(j \omega)=\frac{1}{S_{z}(j \omega)_{+}}\left[\frac{S_{y}(\omega)}{S_{z}(j \omega)_{-}}\right]_{+} .
$$

Спектральна щільність вхідного сигналу:

$$
S_{z}(\omega)=2 \sigma_{y}^{2} \alpha(1+m k)\left[\beta^{2}+\omega^{2} /\left(\alpha^{2}+\omega^{2}\right)\left(m^{2} \alpha^{2}+\omega^{2}\right)\right],
$$

де $\beta^{2}=m \alpha^{2}(m+k) / 1+m k$.

Факторизація спектральної щільності вхідного сигналу:

$$
\begin{gathered}
{\left[S_{z}(j w)_{+}\right]\left[S_{z}(j w)_{-}\right]=2 \sigma_{y}^{2} \alpha(1+m k) \frac{(\beta+j w)(\beta-j w)}{(\alpha+j w)(\alpha-j w)(w \alpha+j w)(m \alpha-j w)}} \\
{\left[S_{z}(j w)_{+}\right]=\sqrt{2 \sigma_{y}^{2} \alpha(1+m k)} \cdot \frac{(\beta+j w)}{(\alpha+j w)(m \alpha+j w)}} \\
{\left[S_{z}(j w)_{-}\right]=\sqrt{2 \sigma_{y}^{2}(1+m k)} \cdot \frac{(\beta-j w)}{(\alpha-j w)(m \alpha-j w)}}
\end{gathered}
$$

Знайдемо відношення спектральної щільності сигналу до факторизованої спектральної щільності з нестійкими складовими:

$$
\begin{aligned}
& {\left[\frac{S_{y}(w)}{S_{z}(j w)_{-}}\right]=\frac{2 \sigma_{y}^{2} \alpha}{\alpha^{2}+w^{2}} \cdot \frac{(\alpha-j w)(m \alpha-j w)}{\sqrt{2 \sigma_{y}^{2} \alpha(1+m k)(\beta-j w)}}=} \\
& =\sqrt{\frac{2 \sigma_{y}^{2} \alpha}{1+m k}} \cdot \frac{m \alpha-j w}{(\alpha+j w)(\beta-j w)}=A \frac{m \alpha-j w}{(\alpha+j w)(\beta-j w)}
\end{aligned}
$$

де $A=\sqrt{\frac{2 \sigma_{y}^{2} \alpha}{1+m k}}$.

Сепарація, тобто розподіл на паралельне з'єднання ланок і відкидання нестійких складових, дозволяє записати:

$$
\left[\frac{S_{y}(w)}{S_{z}(j w)_{-}}\right]=\left[\frac{S_{y}(w)}{S_{z}(j w)_{-}}\right]_{+}+\left[\frac{S_{y}(w)}{S_{z}(j w)_{-}}\right]_{+}=A \frac{m \alpha-j w}{(\alpha+j w)(\beta-j w)} .
$$

Розклавши на дроби, отримаємо:

$\frac{m \alpha-j w}{(\alpha+j w)(\beta-j w)}=\frac{m \alpha}{\alpha+\beta}\left(\frac{1}{\alpha+j w}+\frac{1}{\beta-j w}\right)+\frac{1}{\alpha+\beta}\left(\frac{\alpha}{\alpha+j w}-\frac{\beta}{\beta-j w}\right)=\frac{1}{\alpha+\beta}\left[\frac{\alpha m+1}{\alpha+j w}+\frac{m \alpha-\beta}{\beta-j w}\right]$.

Тоді сепароване вираження відношення спектральної щільності сигналу до факторизованої спектральної щільності зашумленного сигналу має вигляд:

$$
\left[\frac{S_{y}(w)}{S_{z}(j w)_{-}}\right]_{+}=A \frac{\alpha(m+1)}{\alpha+\beta} \frac{1}{\alpha+j w} .
$$

3 врахуванням (1), (3), (5) отримаємо оптимальну частотну характеристику статистичного фільтру інформаційного каналу первинного перетворення при дослідженні томографії:

$$
H(p)=C \frac{1+\tau p}{1+T p},
$$

де коефіцієнт передачі фільтру $C=\frac{m \alpha^{2}(m+1)}{\beta(1+m k)(\alpha+\beta)}$; постійні часу форсування і уповільнення: 
$\tau=\frac{1}{m \alpha} ; T=\frac{1}{\beta}$.

Таким чином, оптимальний статистичний фільтр небілого шуму — це інерційнофорсуюча ланка першого порядку. Його істотний параметр - коефіцієнт відношення постійних часу форсування і інерційності:

$$
\psi=\frac{\tau}{T}=\frac{\beta}{m \alpha}=\sqrt{\frac{m+k}{m(1+m k)}} .
$$

Фільтр може бути представлений у вигляді добутку паралельного з'єднання інерційного і інерційно-диференціюючих ланок і підсилювача з коефіцієнтом передачі (рис. 4)

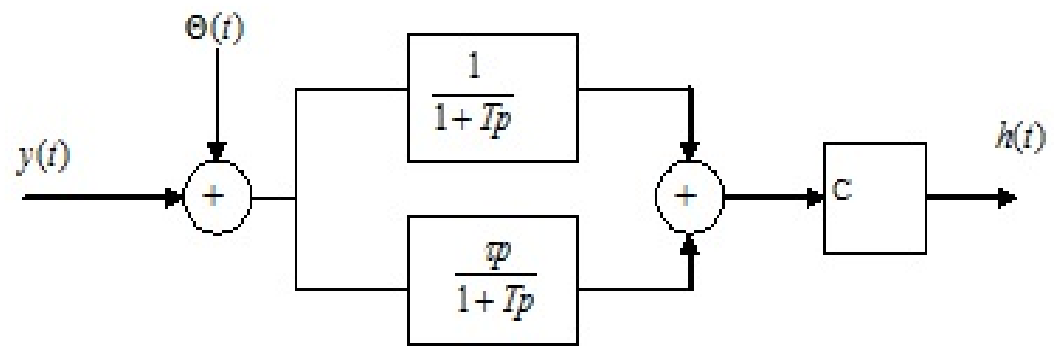

Puc. 4. Варіант оптимального статистичного фільтру каналу виміру

Коефіцієнт передачі оптимального фільтру визначається формулою:

$$
C=\frac{m(m+1)}{\sqrt{m(m+k)}[\sqrt{1+m k}+\sqrt{m(m+k)}]} .
$$

Простежимо вплив зростання відношення перешкода/корисний сигнал на властивості статистичного фільтру небілої перешкоди.

1. $k=0-$ відсутність перешкоди. В цьому випадку витікає, що $\psi=1 ; C=1 ; \tau=T$; $H(p)=1 ; h(t)=y(t)$. Статистичний фільтр є безінерційним підсилювачем 3 коефіцієнтом посилення $C=1$.

2. $k=$ const ; $m \square 1$ але так, що $m k=1$ високочастотне перешкода. Тоді $\psi \rightarrow \frac{1}{\sqrt{2}} ; C \approx 1$ (трохи менше 1). Продовжується наступне зростання інерційно-інтегральних властивостей фільтру.

3. $k \geq 1=$ const але $m \rightarrow \infty-$ істотно високочастотна перешкода. В цьому випадку $\psi=\sqrt{\frac{1+\frac{k}{m}}{1+m k}}=0 ; C \rightarrow \frac{1}{2} ;$ граничне. Тоді $H(p)=\frac{C}{1+T p}$ фільтр $\epsilon$ чисто інерційною ланкою першого порядку (інерційним підсилювачем).

4. $k \rightarrow \infty ; m>1=\mathrm{const}$ - нескінченно велика перешкода, тут

$$
\psi=\sqrt{\frac{1+\frac{m}{k}}{m \frac{1}{k}+m}}=\frac{1}{m} \square 1 ; C \rightarrow 0 .
$$

Фільтр закриває вимірювальний канал від нескінченно великих перешкод.

Зростання співвідношення перешкода/корисний сигнал веде до зростання інерційноінтегральних властивостей фільтра. У границях $(k \rightarrow \infty ; m \rightarrow \infty) ц і$ властивості спочатку інерційні, а потім фільтр спрацьовує як своєрідний вентиль із змінною пропускною спроможністю, відсікаючи вимірювальний канал від небажаних перетворень. Представляє 
інтерес реакція фільтру на одиничну ступінчасту дію. Всупереч поширеній думці про підвищену коливальність систем, синтезованих за методикою Вінера, насправді це далеко не так. Форсування вихідного сигналу обмежується коефіцієнтом передачі фільтру. Добуток коефіцієнта передачі на відношення постійних часу форсування і уповільнення не перевищує одиниці. Початкове значення знаходиться в проміжку між нулем і одиницею. Оцінимо точність виділення корисного сигналу системою, що оцінюється середнім квадратом погрішності $e(t)=h_{T}(t)-h(t)$ та $\sigma_{e}^{2}=\sigma_{h T}^{2}-\sigma_{h}^{2}$. Так якщо $\sigma_{e}^{2}=\sigma_{y}^{2}$, то

$$
\sigma_{h T}^{2}=\int_{-\infty}^{+\infty}|H(j w)|^{2} S_{z}(w) d w .
$$

Виходячи з (6), квадрат модуля частотної характеристики оптимальної системи буде

3 врахуванням (9), отримаємо:

$$
|H(j w)|^{2}=C^{2} \frac{1+\tau^{2} w^{2}}{1+T^{2} w^{2}}
$$

$$
\sigma_{h}^{2}=2 C^{2} \sigma_{y}^{2} \alpha \int_{-\infty}^{+\infty} \frac{1+\tau^{2} w^{2}}{1+T^{2} w^{2}}\left[\frac{1}{\alpha^{2}+w^{2}}+\frac{m k}{m^{2} \alpha^{2}+\varphi^{2}}\right] d w .
$$

Після розкладання на елементарні дроби та перетворень, останній інтеграл набере вигляду:

$$
\begin{aligned}
\sigma_{h}^{2}= & 2 C^{2} \sigma_{y}^{2} \frac{1}{1-\alpha^{2}-T^{2}} \int_{-\infty}^{+\infty}\left[\frac{1}{\alpha^{2}+w^{2}}-\frac{T^{2}}{1+T^{2} w^{2}}\right]\left(1+\tau^{2} w^{2}\right) d w+ \\
& +\frac{m k}{1-m^{2} \alpha^{2} T^{2}} \int_{-\infty}^{+\infty}\left[\frac{1}{m^{2} \alpha^{2}+w^{2}}-\frac{T^{2}}{1+T^{2} w^{2}}\right]\left(1+\tau^{2} w^{2}\right) d w .
\end{aligned}
$$

Після інтегрування:

$$
\sigma_{h}^{2}=2 \pi C^{2} \sigma_{y}^{2}\left[\frac{1+\alpha \tau^{2} / T}{1+\alpha T}+\frac{k\left(1+m \alpha \tau^{2} / T\right)}{1+m \alpha T}\right] .
$$

Визначимо середньоквадратичну погрішність через параметри корисного сигналу і небілої перешкоди:

$$
C^{2}\left[\frac{1+\alpha \tau^{2} / T}{1+\alpha T}+K \frac{1+m \alpha \tau^{2} / T k}{1+m \alpha T}\right] \leq \frac{1}{2 \pi},
$$

де параметри $C, T, \tau^{2}$ виражені формулами (6), одночасно визначають допустиму область змін параметрів перешкоди:

$$
C^{2}\left[\frac{1+\alpha \tau^{2} / T}{1+\alpha T}+\frac{1+m \alpha \tau^{2} / T k}{1+m \alpha T}\right] \leq \frac{1}{2 \pi} .
$$

Тоді при $m=1 ; \tau=T=\frac{1}{\alpha} ; C=\frac{1}{1+k}$ із формули (15) витікає, що

$$
\left(\frac{1}{1+k}\right)^{2}(1+k) \leq 1 / 2 \pi
$$

або $k \geq 2 \pi-1$.

Тобто допустима область визначення параметрів небілої перешкоди $є$ напівпряма: $m=1 ; 2 \pi-1 \leq k \leq \infty$ (16). 
Підставивши параметри перешкоди $k$, які задовольняють допустимій області (26), в (23) знаходимо, що дисперсія помилки фільтрації $\sigma_{e}^{2}$ росте від 0 , при, $k=0$ до дисперсії корисного сигналу, при $k \rightarrow \infty$, тобто при $m=1$ і $2 \pi-1 \leq k \leq \infty$.

\section{Висновки}

Таким чином, в роботі показана ефективність первинної обробки даних, спотворених небілим шумом, структурно оптимальним інерційно-форсуючим фільтром Вінера першого порядку.

\section{Список використаної літератури}

1. Kaufman, A. (Ed.). Volume Visualization. IEEE Computer Society Press, Los Alamitos, CA, 1991. $490 \mathrm{p}$.

2. Laur, D., Hanrahan, P.: Hierarchical splatting: A progressive refinement algorithm for volume rendering. Comput. Graphics 25, 4, 1991, P. 285-288.

3. Gerig, G., Martin, J., Kikinis, R., K"ubler, O., Shenton, M., Jolesz, F. A. Automating segmentation of dual-echo MR head data. In Colchester, A. C. F., Hawkes, D. (Eds.): Information Processing in Medical Imaging, Proc. IPMI "91, Lecture Notes in Computer Science 511, Springer-Verlag, Berlin, 1991, P. 175-187.

4. Haring, S., Viergever, M. A., Kok, J. N. A multiscale approach to image segmentation using Kohonen networks. In Barrett, H. H., Gmitro, A. F. (Eds.), Information Processing in Medical Imaging, Proc. IPMI "93, Lecture Notes in Computer Science 687, Springer-Verlag, Berlin, 1993, P. 212-224.

5. Chen, L. S., Herman, G. T., Reynolds, R. A., Udupa, J. K. Surface sh ding in the cuberille environment. IEEE Comput. Graphics Appl. 5, 12, 1985, P. 33-43.

6. Lorensen, W. E., Cline, H. E. Marching cubes A high resolution 3D surface construction algorithm. Comput. Graphics 21, 4, 1987, P.163-169.

7. Drebin, R. A., Carpenter, L., Hanrahan, P. Volume rendering. Comput. Graphics 22, 4 1988, P. 65-74.

8. Levoy, M. A hybrid ray tracer for rendering polygon and volume data. IEEE Comput. Graphics Appl. 10, 2 1990, P. 33-40.

\section{IMPROVEMENTS OF X-ray COMPUTER TOMOGRAPHY \\ Bagriy V.V., Trikilo A.I., Voloshin R.V.}

\section{Abstract}

$\mathrm{X}$-ray computed tomography (X-ray $\mathrm{CT}$ ) is now the most promising and informative method of diagnosis. With the help of tomography equipment, images of many sections of the patient's body can be obtained that characterize the features of his anatomy and physiology. These snapshots show different organs with extreme clarity, with no organ overlays. Mathematical methods of image processing allow to reconstruct the three-dimensional structure of organs on many parallel sections. A CT scanner includes a radiation source; screen converter, radiation recording; a device for converting initial data into digital code; processor and software that implements a three-dimensional reconstruction algorithm.

Recently, approaches have been developed based on voxel representation of volumes that create three-dimensional images of an object directly from volumetric data. These methods use full information about the intensity values X-ray of a halftone image for rendering surfaces, cuts, or transparent and translucent volumes. The voxel rendering methods that differ mainly in scanning strategy: pixel by pixel (sorting by image) or voxel by voxel (sorting by volume) are perhaps the most informative today. 
A more promising approach is Wavelet-Transform, which creates a multi-scale representation of $3 \mathrm{D}$ objects and allows you to locally adjust the size of the displayed parts and, as a result, reduce the amount of data and rendering time. It should be noted that in order to obtain reliable diagnostic data, the primary image to be processed by the aforementioned methods must have minimal errors related to the features of the hardware of the method. One way to improve the quality of the image taken in computed tomography is to improve primary signal processing, which reduces the impact of various interferences on the results of the study. The primary purpose of this work is to develop primary data processing using an optimal first-order Wiener induction filter to improve X-ray computed tomography.

Thus, the paper shows the efficiency of primary data processing, distorted by nonwhite noise, structurally optimal first-order Wiener filter.

\section{References}

[1] Kaufman, A. (Ed.). (1991). Volume Visualization. IEEE Computer Society Press, Los Alamitos, CA.

[2] Laur, D., Hanrahan, P. (1991) Hierarchical splatting A progressive refinement algorithm for volume rendering. Comput. Graphics 25, 4, 285-288.

[3] Gerig, G., Martin, J., Kikinis, R., K"ubler, O., Shenton, M., Jolesz, F. A. (1991) Automating segmentation of dual-echo MR head data. In Colchester, A. C. F., Hawkes, D. (Eds.): Information Processing in Medical Imaging, Proc. IPMI "91, Lecture Notes in Computer Science 511, 175-187 [in Springer-Verlag, Berlin].

[4] Haring, S., Viergever, M. A., Kok, J. N. (1993) A multiscale approach to image segmentation using Kohonen networks. In Barrett, H. H., Gmitro, A. F. (Eds.), Information Processing in Medical Imaging, Proc. IPMI "93, Lecture Notes in Computer Science 687, 212-224 [in Springer-Verlag, Berlin].

[5] Chen, L. S., Herman, G. T., Reynolds, R. A., Udupa, J. K. (1985) Surface sh ding in the cuberille environment. IEEE Comput. Graphics Appl. 5, 12, 33-43.

[6] Lorensen, W. E., Cline, H. E. (1987) Marching cubes A high resolution 3D surface construction algorithm. Comput. Graphics 21, 4, 163-169.

[7] Drebin, R. A.,Carpenter, L., Hanrahan, P. (1988) Volume rendering. Comput. Graphics 22, 4. 65-74

[8] Levoy, M. (1990) A hybrid ray tracer for rendering polygon and volume data. IEEE Comput. Graphics Appl. 10, 2 33-40. 